\title{
Additive effect of erythropoietin use on exercise-induced endothelial activation and hypercoagulability in athletes
}

\author{
Jules A. A. C. Heuberger ${ }^{1}$ D . Jelle J. Posthuma ${ }^{2} \cdot$ Dimitrios Ziagkos $^{1} \cdot$ Joris I. Rotmans ${ }^{3}$. Johannes M. A. Daniels ${ }^{4}$. \\ Pim Gal ${ }^{1} \cdot$ Frederik E. Stuurman ${ }^{1} \cdot$ Henri M. H. Spronk ${ }^{2} \cdot$ Hugo Ten Cate $^{2} \cdot$ Jacobus Burggraaf $^{1,5} \cdot$ Matthijs Moerland $^{1}$. \\ Adam F. Cohen ${ }^{1,3}$
}

Received: 24 December 2019 / Accepted: 5 June 2020 / Published online: 14 June 2020

(c) The Author(s) 2020

\begin{abstract}
Purpose Recombinant human erythropoietin ( $\mathrm{rHuEPO}$ ) is known to increase thrombotic risk in patients and might have similar effects in athletes abusing the drug. rHuEPO is prohibited by anti-doping legislation, but this risk has not been investigated thoroughly. This analysis was designed to evaluate whether rHuEPO impacts hemostatic profile and endothelial and platelet activation markers in trained subjects, and whether the combination with exercise affects exercise induced alterations. Methods This double-blind, randomized, placebo-controlled trial enrolled healthy, trained male cyclists aged 18-50 years. Participants were randomly allocated (1:1) to receive subcutaneous injections of rHuEPO (epoetin- $\beta$; mean dose $6000 \mathrm{IU}$ per week) or placebo $(0.9 \% \mathrm{NaCl})$ for 8 weeks. Subjects performed five maximal exercise tests and a road race, coagulation and endothelial/platelet markers were measured at rest and directly after each exercise effort.

Results rHuEPO increased P-selectin $(+7.8 \%(1.5-14.5), p=0.02)$ and E-selectin $(+8.6 \%(2.0-15.7), p=0.01)$ levels at rest. Maximal exercise tests significantly influenced all measured coagulation and endothelial/platelet markers, and in the rHuEPO group maximal exercise tests led to $15.3 \%((7.0-24.3 \%), p=0.0004)$ higher E-selectin and 32.1\% ((4.6-66.8\%), $p=0.0207$ ) higher Platelet factor 4 (PF4) levels compared to the placebo group.

Conclusion In conclusion, rHuEPO treatment resulted in elevated E- and P-selectin levels in trained cyclists, indicating enhanced endothelial activation and/or platelet reactivity. Exercise itself induces hypercoagulability, and the combination of rHuEPO and exercise increased E-selectin and PF4 levels more than either intervention alone. Based on this, exercise potentially increases thrombotic risk, a risk that might be enhanced in combination with rHuEPO use.
\end{abstract}

Keywords Erythropoietin $\cdot$ Hemostasis $\cdot$ Exercise $\cdot$ Endothelial activation $\cdot$ Coagulation

\section{Abbreviations}

aPTT Activated partial thromboplastin time

beta-TG Beta thromboglobulin

EM Estimated means

Communicated by Fabio Fischetti.

Electronic supplementary material The online version of this article (https://doi.org/10.1007/s00421-020-04419-0) contains supplementary material, which is available to authorized users.

Jules A. A. C. Heuberger

jheuberger@chdr.nl

1 Centre for Human Drug Research, Zernikedreef 8, 2333 CL Leiden, The Netherlands

2 Departments of Internal Medicine and Biochemistry, Cardiovascular Research Institute Maastricht (CARIM), Maastricht University, Maastricht, The Netherlands
$\mathrm{F} 1+2 \quad$ Prothrombin fragment $1+2$

FVIII Factor VIII

$\mathrm{Hb} \quad$ Hemoglobin

Ht Hematocrit

iCAM Intercellular adhesion molecule 1

IU International units

LPS Lipopolysaccharide

NTR Nederlands Trial Register (Dutch Trial Registry)
3 Department of Internal Medicine, Leiden University Medical Centre, Leiden, The Netherlands

4 Department of Pulmonary Diseases, VU University Medical Centre, Amsterdam, The Netherlands

5 Leiden Academic Centre for Drug Research, Leiden, The Netherlands 


$\begin{array}{ll}\text { PF4 } & \text { Platelet factor } 4 \\ \text { PT } & \text { Prothrombin time } \\ \text { rHuEPO } & \text { Recombinant human erythropoietin } \\ \text { TAT } & \text { Thrombin:Antithrombin } \\ \text { vCAM } & \text { Vascular cell adhesion molecule 1 } \\ \text { VO2max } & \text { Maximal oxygen uptake } \\ \text { vWF } & \text { Von Willebrand Factor antigen }\end{array}$

\section{Introduction}

Recombinant human erythropoietin (rHuEPO) is on the World Anti-Doping Agency's Prohibited List as it is considered to possess performance enhancing properties and represents a potential health risk to athletes (World AntiDoping Agency 2018). Effects on actual performance, however, are not indisputably proven in athletes (Heuberger et al. 2013). Moreover, in a recent study we found that although rHuEPO treatment improved laboratory tests of maximal exercise, more relevant endurance performance variables such as time trial and road race performance remained unchanged (Heuberger et al. 2017). Similarly, although there is evidence that rHuEPO increases thrombogenicity and risk of stroke in patients (Pfeffer et al. 2009), it is unclear whether athletes abusing rHuEPO could also display increased thrombotic risk. It would be informative to understand whether rHuEPO activates coagulation and endothelial cells in athletes, especially given that exercise itself is known to impact the hemostatic profile (Posthuma et al. 2015). Although exercise is generally accepted to be beneficial for health, cases of thrombotic events induced by exercise have been reported. This is likely due to the effects of exercise on the hemostatic profile, which seem to be correlated with exercise intensity (Posthuma et al. 2015). Intense exercise, often performed by athletes, in combination with increased erythropoiesis and subsequent hemoconcentration after rHuEPO use might increase the risk for thrombotic events. Additionally, potential direct effects of rHuEPO on pathways involved in coagulation and endothelial and platelet activation could add to this risk. In the current analysis as part of the same study (Heuberger et al. 2017) we investigated the effects of rHuEPO, exercise and the combined effects of rHuEPO and exercise in trained cyclists on markers of coagulation and endothelial and platelet activation.

\section{Materials and methods}

\section{Data sharing statement}

The trial protocol can be found at:

http://chdr.nl/library/protocol-to-study-chdr1514-theeffects-of-eryth ropoi etin-on-cycling-performanc e-of-well-trained-cyclists-a-randomized-double-blind-place bo-controlled-parallel-trial/download.

The data that support the findings of this study are available from the corresponding author upon reasonable request.

\section{Study design and participants}

The study design was previously described (Heuberger et al. 2017). Briefly, forty-eight healthy male cyclists between 18 and 50 years participated in a double-blind, randomized, placebo controlled, parallel, single center study. Among the inclusion criteria were hemoglobin $(\mathrm{Hb})$ concentration between 8.0 and $9.8 \mathrm{mmol} / \mathrm{L}$ (equivalent to $12.8-15.7 \mathrm{~g} / \mathrm{dL}$, within the normal range for this population) and hematocrit (Ht) level below $48 \%$ at screening and not using medication that could potentially interact with the study drugs or study assessments. Health status was determined by medical history and physical examinations; participants were excluded if they had any clinically relevant pre-existing condition, including cardiovascular, pulmonary, muscle, metabolic, hematological or inflammatory disease.

\section{Randomization and masking}

Participants were randomly assigned in a balanced manner to either rHuEPO or placebo treatment. A stratified randomization block was used with participants aged 18-34 (inclusive) and aged 35-50 (inclusive) to reduce variability between groups due to age differences.

\section{Procedures}

\section{Treatment}

Treatments were as described previously (Heuberger et al. 2017). Briefly, participants received weekly abdominal subcutaneous injections of Epoetin beta (NeoRecormon, Roche, Basel, Switzerland) prepared from multidose vials or saline $(0.9 \% \mathrm{NaCl})$ for 8 weeks. $\mathrm{Hb}$ and $\mathrm{Ht}$ were measured before each dose and only available to dedicated un-blinded personnel. The target $\mathrm{Hb}$ in the rHuEPO group was an increase of 10-15\% compared to the baseline $\mathrm{Hb}$ concentration, measured with the HemoCue $\mathrm{Hb} 201+$ analyzer (Radiometer Benelux B.V., Zoetermeer, the Netherlands). In the first 4 weeks, participants received a 5000 international units (IU) dose per injection, after which it could be increased to $6000 \mathrm{IU}, 8000 \mathrm{IU}$ or $10000 \mathrm{IU}$ to reach the target range. $\mathrm{rHuEPO}$ dose was $2000 \mathrm{IU}$ if $\mathrm{Hb}$ was in the target range. For safety reasons, participants received a placebo injection if the $\mathrm{Hb}$ was above the target range, or if $\mathrm{Ht}$ was equal to or exceeded $52 \%$, measured by the Hematokrit 200 (Hettich Benelux B.V., Geldermalsen, the Netherlands). rHuEPO and placebo were visually indistinguishable (both colorless 
solutions) and dosage changes (changes in injected volume) were also randomly assigned to placebo participants.

All participants also took open-label daily oral doses of $200 \mathrm{mg}$ ferrous fumarate and $50 \mathrm{mg}$ ascorbic acid (both from Pharmachemie B.V., Haarlem, The Netherlands) during the study to make sure participants were not iron deficient during the study.

\section{Maximal graded exercise test}

Maximal graded exercise tests were performed on a Monark LC4r ergometer (COSMED, Rome, Italy) during screening, at baseline (up to 14 days before first dose) and during the treatment period at $11,25,39$ and 53 days ( \pm 1 day) after the first dose administration. The protocol started with 1-min rest without pedaling, followed by 2 min warm-up at 75 Watts. The pedaling resistance was then increased to 175 Watts, and 25 watts every $5 \mathrm{~min}$. Cadence had to be maintained between 70 and $90 \mathrm{rpm}$. The test stopped when cadence could not be maintained above $70 \mathrm{rpm}$ or when a participant terminated the test. Participants then pedaled at 50 Watts during a 3-min recovery. Blood for coagulation and endothelial markers was drawn from an intravenous cannula in the right forearm before and directly after the exercise tests.

\section{Mont ventoux race}

Approximately 12 days after the last dose participants took part in a road stage of $110 \mathrm{~km}$ in the French Provence (total elevation gain $1524 \mathrm{~m}$ ), after which they competitively climbed the Mont Ventoux (Vaucluse département, France) in an open course via Bédoin, France, bridging an altitude of $1610 \mathrm{~m}$ over $21.5 \mathrm{~km}$. Blood for coagulation and endothelial markers was drawn before the $110 \mathrm{~km}$ stage and at the top of the Mont Ventoux.

\section{Coagulation and endothelial and platelet markers}

Markers for coagulation and platelet activation determined were prothrombin time (PT), activated partial thromboplastin time (aPTT), D-dimer, fibrinogen, Beta thromboglobulin (beta-TG), prothrombin fragment $1+2(\mathrm{~F} 1+2)$, Factor VIII (FVIII), platelet factor 4 (PF4) and Thrombin:Antithrombin (TAT). Endothelial activation markers determined were E-selectin, intercellular adhesion molecule 1 (iCAM), P-selectin, thrombomodulin, vascular cell adhesion molecule 1 (vCAM) and Von Willebrand Factor antigen (vWF). For more detail on the assays, see the Supplemental Material.

\section{Blood sample handling quality control}

Soluble CD40L is primarily produced and released by activated platelets. Numerous studies have reported increased $\mathrm{sCD} 40 \mathrm{~L}$ in various clinical conditions and diseases associated with platelet activation. When comparing two commercially available sCD40L ELISA kits (Thermo Fisher and RnD systems), all test samples collected in CTAD tubes showed SCD40L levels below or around the lower level of quantification. Further investigation indicated that when comparing CTAD and serum samples from the same donors, similar low sCD40L levels were detected in the CTAD samples, but significant SCD40L levels were present in the serum samples, demonstrating the efficacy of the used ELISA kits. These data indicate that careful sample handling procedures and collection in CTAD tubes resulted in minimal platelet activation and subsequent $\mathrm{SCD} 40 \mathrm{~L}$ release, and that minimal in vivo $\mathrm{SCD} 40 \mathrm{~L}$ release had taken place in the study participants.

\section{Statistical analysis}

Participants with at least one available measurement were included in the analyses. For rHuEPO effects, pre-exercise data were analyzed with a mixed model analysis of variance with treatment, time and treatment by time as fixed factors, participants as random factor and the pre-value as covariate for treatment effects. For exercise effects, the analysis was performed on the placebo group, with a mixed model analysis of variance, time as fixed factor, participants as random factor and the pre-value as covariate. For combined rHuEPO and exercise effects, the analysis was performed on the postexercise measures with a mixed model analysis of variance with treatment, time and treatment by time as fixed factors, participants as random factor and the pre-value as covariate for treatment effects. The contrast that is calculated within the models is placebo versus $\mathrm{rHuEPO}$, or before versus after exercise.

Results of statistical models are reported as estimated means (EM) at the different time points per intervention and estimates of the difference between treatments over the whole time period, including 95\% confidence intervals (logtransformed parameters are reported in percentage) and the $p$ value of the contrasts.

When $95 \%$ confidence intervals are presented, they reflect the estimated difference between the two treatment groups, with a significance level of $p<0.050$. All calculations were performed using SAS for windows V9.4 (SAS Institute, Inc., Cary, NC, USA). 


\section{Results}

\section{rHuEPO effects}

A total of 48 participants were included in the analyses (24 in the rHuEPO group and 24 in the placebo group). One participant withdrew after the fourth dose administration, all other 47 participants completed the study. Participants were trained cyclist, confirmed by their average baseline maximal power output values of $335.07 \mathrm{~W}$ (SD 33.40) and maximal oxygen uptake (VO2max) of $55.63 \mathrm{~mL} / \mathrm{min}$ per kg (SD 4.80), with average recorded cycling activity of $4.9 \mathrm{~h}$ and $5.9 \mathrm{~h}$ for rHuEPO and placebo groups, respectively. rHuEPO treatment had clear effects on several variables in rest as we have partly reported previously (Heuberger et al. 2017). Average $\mathrm{Hb}(+12 \%)$ and $\mathrm{Ht}$ $(+16 \%)$ increased upon rHuEPO treatment and was significantly elevated compared to placebo with $0.6 \mathrm{mmol} / \mathrm{L}$ (0.44-0.77, $p=<0.0001$ ) (equivalent to $0.97 \mathrm{~g} / \mathrm{dL}$ ) and $3.3 \%(2.5-4.1, p=<0.0001)$, respectively. In contrast, platelet count was not affected by rHuEPO treatment (see Supplemental Table 1). rHuEPO significantly increased resting levels of P-selectin $(+7.8 \%(1.5-14.5), p=0.02)$ and E-selectin $(+8.6 \%(2.0-15.7), p=0.01)$ compared to placebo, but iCAM and vCAM were not significantly altered by rHuEPO treatment, see Table 1 . aPTT and coagulation markers TAT and D-dimer remained unchanged, as did specific platelet activation markers PF4 and Beta-TG, see Supplemental Table 1.

\section{Exercise effects}

Exercise by itself induced significant alterations in hemostatic profile, as can be concluded from the observations in the placebo treated participants. Exercise increased TAT, D-Dimer, PF4 and Beta-TG levels, and decreased aPTT in this group. Endothelial markers E- and P-selectin were also increased by exercise, as well as ICAM and vCAM. All measured markers were significantly affected by the maximal exercise test, whereas the race only had a significant effect on a subset of markers. The direction of these significant effects was the same for the exercise test and race, although there seem to be differences in magnitude of the effect for some markers: aPTT (percentage change after maximal exercise test and race: $-12.4 \%$ and $-15.5 \%$, respectively), Beta-TG (92.6\% and $21.2 \%$ ), FVIII (128.7\% and $181.1 \%$ ), P-selectin (12.2\% and $34.1 \%)$, PF4 (192.4\% and $118.9 \%)$, TAT (504.6\% and $159.7 \%$ ) and $\mathrm{vWF}$ (82.9\% and $166.0 \%)$. See Table 2 for an overview of all changes in markers due to both the exercise test and the race and Figs. 1, 2, 3, 4 for a graphical representation of these effects for a selection of markers. Table 2 also shows a comparison of these observed effects with existing literature data. This comparison shows that the direction of the observed effect in the current study is supported by the data available, although the magnitude of the effect differs for some specific markers.

\section{Effect of combination of rHuEPO and exercise}

The combination of rHuEPO treatment and exercise showed larger changes in several markers compared to exercise alone (in the placebo group). Namely, E-selectin levels post-exercise were $15.3 \%$ higher in the rHuEPO treated group than in the placebo group, and $32.1 \%$ higher for PF4, see Table 3 and Figs. 1, 3. For the other markers, there was no difference in post-exercise values between the rHuEPO and placebo groups, see Supplemental Table 2.

\section{Discussion}

Although regular exercise is considered healthy, sporadic cases of exercise-induced thrombotic events, such as ischemic stroke, venous thromboembolism and myocardial infarction have been reported. This is probably related to changes in hemostasis that have been observed after exercise, especially high intensity exercise, possibly in combination with additional predisposing cardiovascular risk factors (Posthuma et al. 2015). One such risk factor could be pharmacological treatment with hematopoietic factors, such as rHuEPO. In anemic patients, rHuEPO increased thrombotic risk, probably in part as a result of hemoconcentration. A meta-analysis of 9353 patients in 57 randomized placebo-controlled trials showed that treatment with erythropoietin was associated with a significantly increased thromboembolic risk [relative risk: 1.67; 95\% confidence interval: 1.35 to 2.06] (Bohlius et al. 2006). However, whether rHuEPO also increases thrombotic risk in healthy athletes is unknown. Although the meta-analysis only included studies that used dose levels between 30.000 and $70.000 \mathrm{IU}$ per week, more than allegedly used by athletes (likely more in the range of 10.000 IU per week (Hamilton and Coyle 2012)), this question is relevant given the lack of information on effects in athletes. There is no general consensus on predictive molecular markers for thromboembolic risk, but from a mechanistic pointof-view activation of coagulation pathways, endothelial cells and platelets could ultimately determine thrombotic risk. Therefore, we investigated the effects of rHuEPO doping use on coagulation and endothelial/platelet activation markers, both in rest and after intense exercise, in the same study of which we published the results on the effects of rHuEPO on cycling performance in trained 


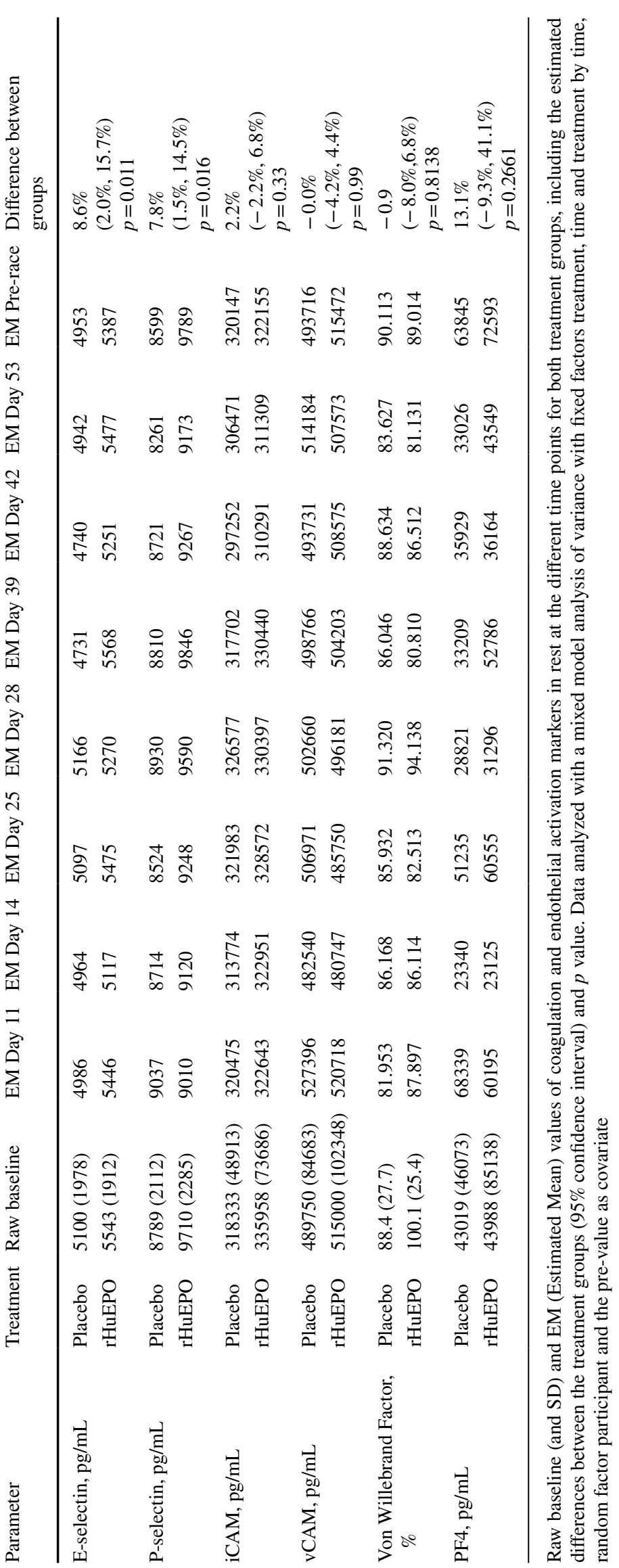


Table 2 Effects of different types of exercise on hemostatic profile: current study and literature data

\begin{tabular}{|c|c|c|c|c|c|}
\hline \multirow[t]{2}{*}{ Marker } & \multicolumn{2}{|l|}{ Current study } & \multicolumn{3}{|l|}{ Literature data } \\
\hline & Exercise test & Race & Maximal exercise & $\begin{array}{l}\text { Short ( } \leq 60 \mathrm{~min}) \text { sub- } \\
\text { maximal exercise }\end{array}$ & $\begin{array}{l}\text { Long (>60 min) sub- } \\
\text { maximal exercise }\end{array}$ \\
\hline Platelet count & NA & $10.6 \%[1.1 \% ; 20.9 \%]$ & $\begin{array}{l}25 \text { to } 27 \% \text { (Herren } \\
\text { et al. 1992; Wang } \\
\text { et al. 1994) }\end{array}$ & $\begin{array}{l}26 \% \text { (Cadroy et al. } \\
\text { 2002) }\end{array}$ & $\begin{array}{l}\text { 12\% (Posthuma et al. } \\
\text { 2014) }\end{array}$ \\
\hline $\begin{array}{l}\text { Activated partial throm- } \\
\text { boplastin time }\end{array}$ & $\begin{array}{l}-12.4 \%[-14.1 \% \\
-10.6 \%]\end{array}$ & $\begin{array}{l}-15.5 \%[-28.2 \% \\
-0.5 \%]\end{array}$ & $\begin{array}{l}-\mathbf{6 \%} \text { (Menzel and } \\
\text { Hilberg 2011; } \\
\text { Handa et al. 1992) }\end{array}$ & $\begin{array}{l}\mathbf{- 5} \text { to } \mathbf{- 8 \%} \text { (Handa } \\
\text { et al. 1992; Menzel } \\
\text { and Hilberg 2011) }\end{array}$ & NA \\
\hline Prothrombin time & $\begin{array}{l}-2.1 \%[-2.9 \% \\
-1.3 \%]\end{array}$ & $1.5 \%[-1.2 \% ; 4.2 \%]$ & $\begin{array}{l}-1 \text { to }-3 \% \text { (Handa } \\
\text { et al. 1992; Menzel } \\
\text { and Hilberg 2011) }\end{array}$ & $\begin{array}{l}\text { 2\% (Handa et al. } \\
\text { 1992; Menzel and } \\
\text { Hilberg 2011) }\end{array}$ & NA \\
\hline Fibrinogen & $7.0 \%[4.4 \% ; 9.6 \%]$ & $\begin{array}{l}-7.6 \%[-15.5 \% \\
1.2 \%]\end{array}$ & $\begin{array}{l}\mathbf{1 2 \%} \text { (Gunga et al. } \\
\text { 2002) }\end{array}$ & NA & $\begin{array}{l}2 \% \text { (Rocker et al. } \\
1986)\end{array}$ \\
\hline D-dimer & $\begin{array}{l}43.0 \%[25.5 \% \\
\quad 62.9 \%]\end{array}$ & $\begin{array}{l}-2.5 \%[-24.3 \% \\
25.6 \%]\end{array}$ & NA & $\begin{array}{l}\sim \mathbf{1 5 0 \%} \text { (Parker et al. } \\
\text { 2012) }\end{array}$ & NA \\
\hline Beta Thromboglobulin & $\begin{array}{l}92.6 \%[63.8 \% \\
126.3 \%]\end{array}$ & $\begin{array}{l}21.2 \%[16.9 \% \\
135.1 \%]\end{array}$ & $\begin{array}{l}\mathbf{6 0} \text { to } \mathbf{8 5 \%} \text { (Herren } \\
\text { et al. 1992; Wang } \\
\text { et al. 1994) }\end{array}$ & $\begin{array}{l}21 \% \text { (Cadroy et al. } \\
\text { 2002) }\end{array}$ & NA \\
\hline E-selectin & $7.1 \%[4.3 \% ; 9.9 \%]$ & $\begin{array}{l}4.7 \%[-16.1 \% \\
30.7 \%]\end{array}$ & $\begin{array}{l}4 \text { to } \mathbf{1 0} \% \text { (Li et al. } \\
\text { 2007; Jilma et al. } \\
\text { 1997) }\end{array}$ & $\begin{array}{l}-4 \% \text { (Jilma et al. } \\
\text { 1997) }\end{array}$ & $\begin{array}{l}\text { 16\% (Nielsen and } \\
\text { Lyberg 2004) }\end{array}$ \\
\hline iCAM & $8.6 \%[6.5 \% ; 10.9 \%]$ & $4.4 \%[-4.7 \% ; 14.4 \%]$ & $\begin{array}{l}11 \text { to } \mathbf{2 4 \%} \text { (Jilma } \\
\text { et al. 1997; Rehman } \\
\text { et al. 1997) }\end{array}$ & $\begin{array}{l}-4 \% \text { (Jilma et al. } \\
\text { 1997) }\end{array}$ & $\begin{array}{l}\text { 5\% (Nielsen and } \\
\text { Lyberg 2004) }\end{array}$ \\
\hline vCAM & $7.6 \%[5.7 \% ; 9.4 \%]$ & $7.3 \%[-2.3 \% ; 17.9 \%]$ & $\begin{array}{l}\text { 10\% (Jilma et al. } \\
1997 \text { ) }\end{array}$ & 1\% (Jilma et al. 1997) & $\begin{array}{l}\text { 22\% (Nielsen and } \\
\text { Lyberg 2004) }\end{array}$ \\
\hline $\begin{array}{l}\text { Prothrombin fragment } \\
1+2\end{array}$ & $\begin{array}{l}88.0 \%[64.3 \% \\
115.2 \%]\end{array}$ & $\begin{array}{l}\text { 9.8\% }[-12.6 \% \\
38.1 \%]\end{array}$ & $\begin{array}{l}17 \text { to } 19 \% \text { (Rocker } \\
\text { et al. 1996; Li et al. } \\
\text { 2007) }\end{array}$ & NA & NA \\
\hline Factor VIII & $\begin{array}{l}128.7 \%[104.4 \% \\
155.9 \%]\end{array}$ & $\begin{array}{l}181.1 \%[147.8 \% \\
218.9 \%]\end{array}$ & $\begin{array}{l}\text { 63\% (Menzel and } \\
\text { Hilberg 2011) }\end{array}$ & $\begin{array}{l}34 \text { to } 38 \% \text { (Hegde } \\
\text { et al. 2001; Menzel } \\
\text { and Hilberg 2011) }\end{array}$ & NA \\
\hline P-selectin & $12.2 \%[9.1 \% ; 15.4 \%]$ & $\begin{array}{l}34.1 \%[16.2 \% \\
54.6 \%]\end{array}$ & $\mathbf{2 1 \%}$ (Li et al. 2007) & $\begin{array}{l}\sim 70 \% \text { (Parker et al. } \\
\text { 2012) }\end{array}$ & $\begin{array}{l}\text { 44\% (Nielsen and } \\
\text { Lyberg 2004) }\end{array}$ \\
\hline PF4 & $\begin{array}{l}192.4 \%[137.2 \% \\
260.6 \%]\end{array}$ & $\begin{array}{l}\text { 118.9\% [57.2\%; } \\
\text { 205.0\%] }\end{array}$ & $\begin{array}{l}\text { 85\% (Wang et al. } \\
\text { 1994) }\end{array}$ & NA & $\begin{array}{l}\text { 102\% (Rocker et al. } \\
\text { 1986) }\end{array}$ \\
\hline Thrombin:Antithrombin & $\begin{array}{l}504.6 \%[386.6 \% \\
651.3 \%]\end{array}$ & $\begin{array}{l}\text { 159.7\% [65.2\%; } \\
\text { 308.5\%] }\end{array}$ & $\begin{array}{l}32 \text { to } \mathbf{1 0 8 \%} \text { (Rocker } \\
\text { et al. 1996; Menzel } \\
\text { and Hilberg 2011) }\end{array}$ & $\begin{array}{l}16 \text { to } 43 \% \text { (Cadroy } \\
\text { et al. 2002; Menzel } \\
\text { and Hilberg 2011) }\end{array}$ & NA \\
\hline Thrombomodulin & $13.5 \%[9.8 \% ; 17.4 \%]$ & $\begin{array}{l}6.0 \%[-20.6 \% \\
\quad 41.5 \%]\end{array}$ & NA & NA & NA \\
\hline Von Willebrand Factor & $\begin{array}{l}82.9 \%[64.1 \% \\
103.8 \%]\end{array}$ & $\begin{array}{l}166.0 \%[125.1 \% \\
214.2 \%]\end{array}$ & NA & NA & NA \\
\hline
\end{tabular}

Current study: Estimated percentage change due to exercise compared to rest in the placebo group [95\% confidence interval of the effect size]. Literature data percentage change due to exercise compared to rest. Figures in bold depict a significant change. NA not available

cyclists (Heuberger et al. 2017). The dose regimen in our study is consistent with known practices in professional cycling (Hamilton and Coyle 2012). We quantified molecular markers for activation of the coagulation system and the endothelium after rHuEPO use, exercise, and a combination of both, which may ultimately help us understanding the thrombotic risk of these interventions. This study did not evaluate vascular reactivity from a functional perspective, with a focus on the effect of rHuEPO use and exercise on NO metabolism.

Evaluating the effects of rHuEPO alone, we found an increase in P-selectin and E-selectin, but no clear effects on platelet and endothelial activation by other markers. Exercise alone clearly impacted the hemostatic profile of participants in our study, similar to what has previously been reported (Posthuma et al. 2015) and as shown 


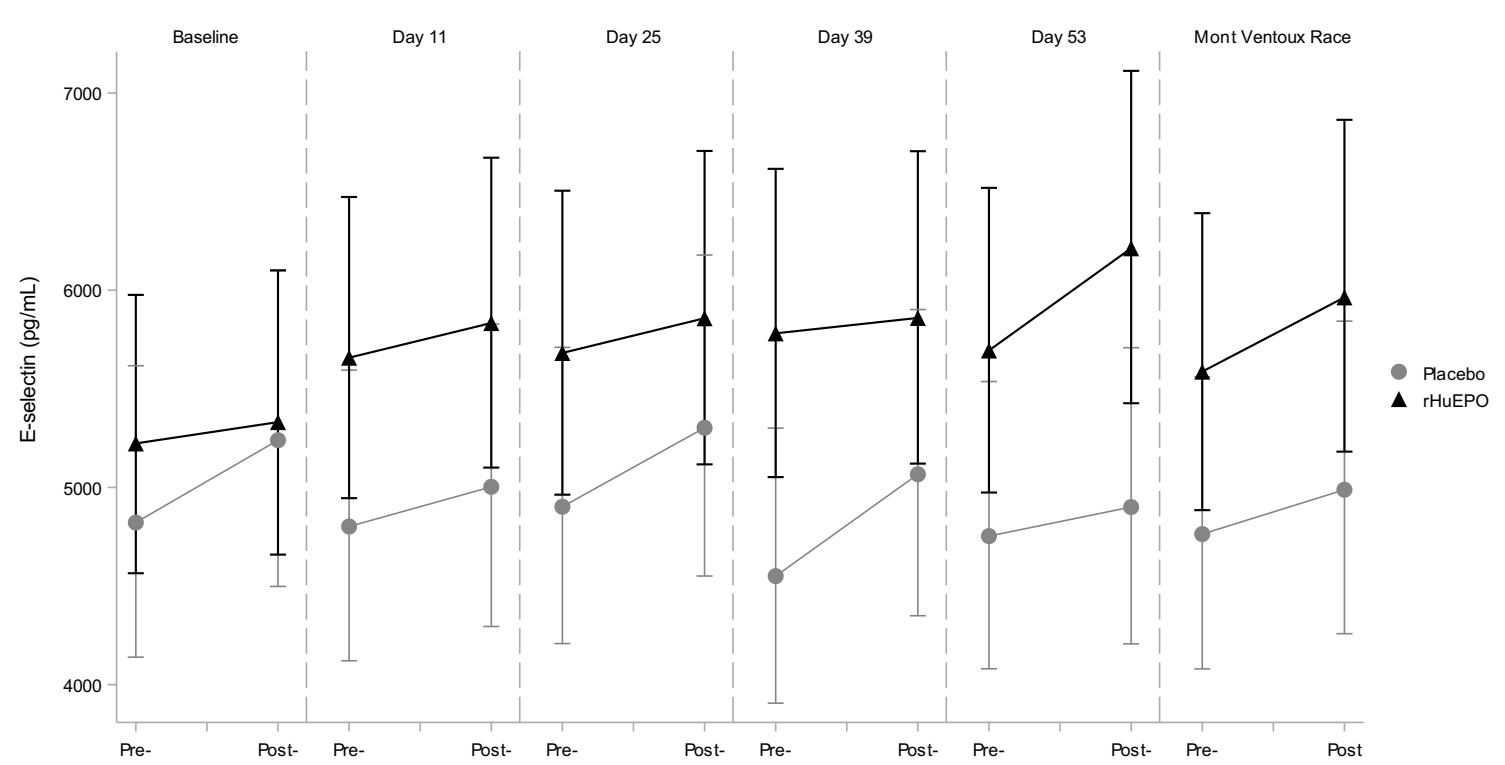

Fig. 1 Exercise and rHuEPO effects on E-selectin levels (pg/mL). Pre- and post- exercise levels of E-selectin for the maximal graded exercise test at baseline, 11, 25, 39 and 53 days and the Mont Ventoux race for rHuEPO and placebo groups

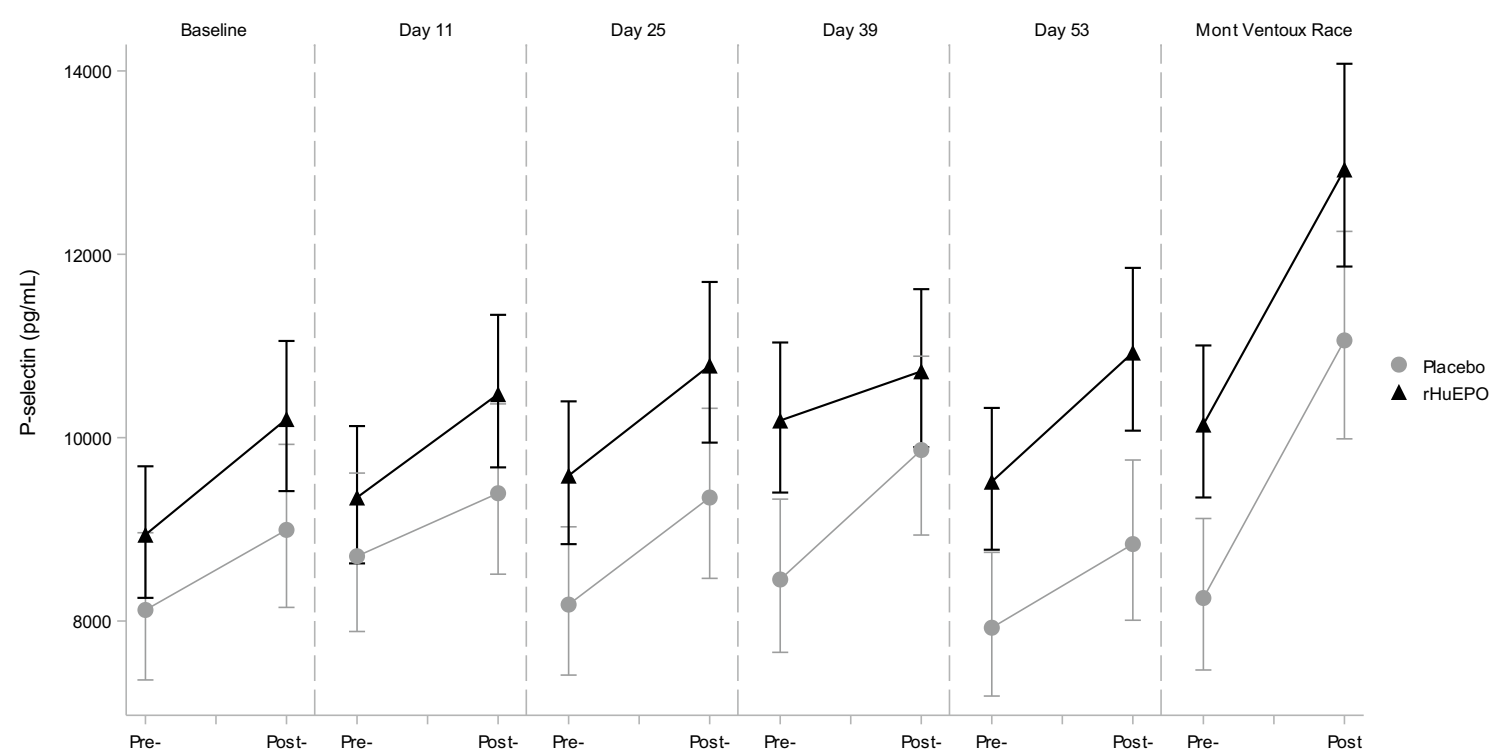

Fig. 2 Exercise and rHuEPO effects on P-selectin levels (pg/mL). Pre- and post- exercise levels of P-selectin for the maximal graded exercise test at baseline, 11, 25, 39 and 53 days and the Mont Ventoux race for rHuEPO and placebo groups

in Table 2. Our study showed significant changes in all measured markers in the maximal exercise test. Additionally, based on our study and the existing literature, it seems that the effect size on specific markers can depend on the type (duration and intensity) of exercise performed. When combining rHuEPO treatment and exercise, the effects observed on E-selectin were additive, but not synergistic. In addition, PF4 was not significantly increased by rHuEPO alone; however, when rHuEPO and exercise were combined, the increase in PF4 was larger than for exercise alone.

\section{Clinical relevance}

\section{Effects on P-selectin}

P-selectin is a cellular adhesion molecule enhancing coagulation and activation of leukocyte integrins. P-selectin is 


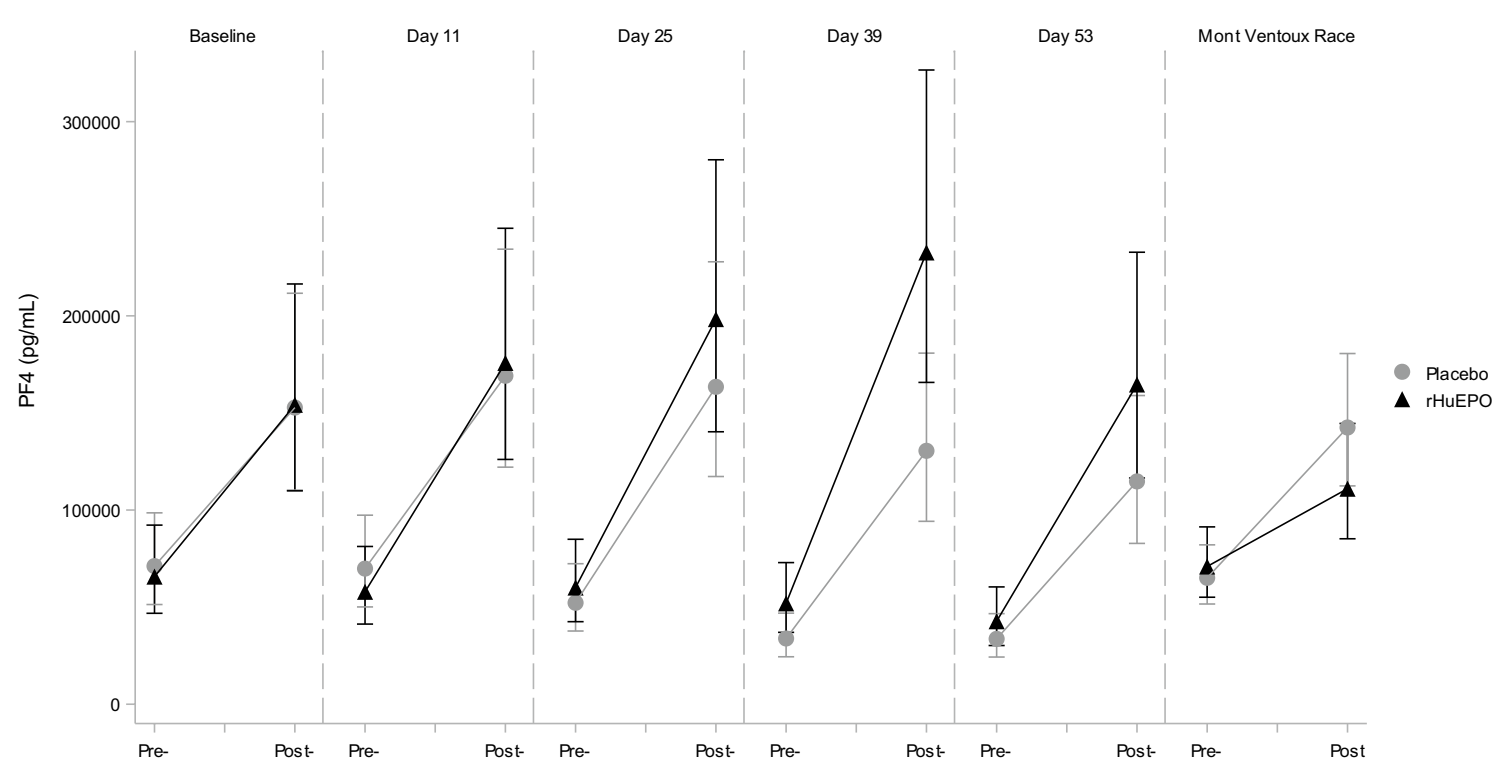

Fig. 3 Exercise and rHuEPO effects on Platelet Factor 4 (pg/mL). Pre- and post- exercise levels of platelet factor 4 (PF4) for the maximal graded exercise test at baseline, 11, 25, 39 and 53 days and the Mont Ventoux race for rHuEPO and placebo groups

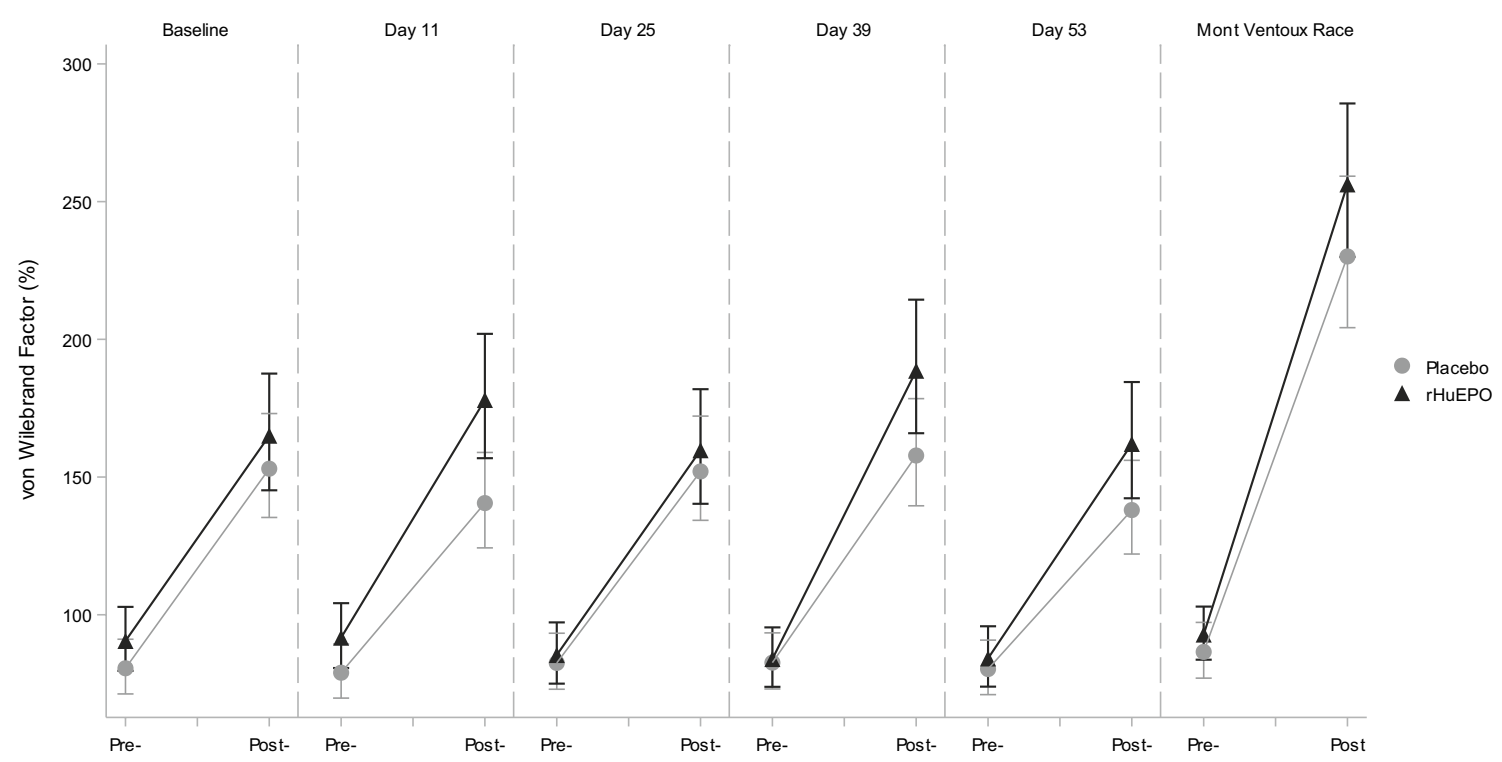

Fig. 4 Exercise and rHuEPO effects on von Willebrand Factor (\%). Pre- and post- exercise levels of von Willebrand Factor (vWF) for the maximal graded exercise test at baseline, 11, 25, 39 and 53 days and the Mont Ventoux race for rHuEPO and placebo groups

mainly released form platelets, but also endothelial cells secrete P-selectin upon activation. Higher P-selectin levels may be an independent risk factor for atherosclerotic disease (Bielinski et al. 2015). In our study, the estimated mean levels of P-selectin after rHuEPO treatment were $9376 \mathrm{pg} / \mathrm{mL}$, an increase of $8 \%$ compared to placebo. The exercise test increased P-selectin by $12.2 \%$, but the combination of exercise and rHuEPO did not lead to a significant increase compared to exercise alone. Nevertheless, rHuEPO increased
P-selectin levels consistently over the treatment period and to a similar magnitude as the exercise test does.

Though our data clearly demonstrate that both exercise and rHuEPO treatment increased P-selectin levels, the physiological impact of this increase is not clear. Absolute levels of P-selectin seem difficult to compare between studies. Collection should be done in citrated plasma to avoid platelet activation in the tube leading to artificially elevated P-selectin levels (Caine and Blann 2003). 
Table 3 Effects of exercise on markers per treatment group

\begin{tabular}{|c|c|c|c|c|c|c|c|}
\hline Parameter & Treatment & Raw baseline & $\begin{array}{l}\text { EM } \\
\text { Day } 11\end{array}$ & $\begin{array}{l}\text { EM } \\
\text { Day } 25\end{array}$ & $\begin{array}{l}\text { EM } \\
\text { Day } 39\end{array}$ & $\begin{array}{l}\text { EM } \\
\text { Day } 53\end{array}$ & Difference between groups \\
\hline \multirow[t]{2}{*}{ E-selectin, pg/mL } & Placebo & $5584(2104)$ & 5022 & 5333 & 5086 & 4919 & \multirow{2}{*}{$\begin{array}{l}15.3 \% \\
(7.0 \%, 24.3 \%) \\
p=0.0004\end{array}$} \\
\hline & rHuEPO & $5613(2001)$ & 5731 & 5819 & 5800 & 6129 & \\
\hline \multirow[t]{2}{*}{ P-selectin, pg/mL } & Placebo & $9214(2105)$ & 9789 & 9719 & 10280 & 9211 & \multirow{2}{*}{$\begin{array}{l}5.2 \% \\
(-2.9 \%, 13.9 \%) \\
p=0.2077\end{array}$} \\
\hline & rHuEPO & $10300(1884)$ & 10027 & 10370 & 10203 & 10399 & \\
\hline \multirow[t]{2}{*}{ iCAM, pg/mL } & Placebo & 339917 (46981) & 338125 & 365918 & 350488 & 346019 & \multirow{2}{*}{$\begin{array}{l}-0.9 \% \\
(-7.0 \%, 5.5 \%) \\
p=0.7677\end{array}$} \\
\hline & rHuEPO & 375217 (78950) & 342709 & 357497 & 337634 & 349506 & \\
\hline \multirow[t]{2}{*}{ vCAM, pg/mL } & Placebo & $520833(76355)$ & 551062 & 565671 & 546102 & 554070 & \multirow{2}{*}{$\begin{array}{l}-3.6 \% \\
(-9.2 \%, 2.4 \%) \\
p=0.2302\end{array}$} \\
\hline & rHuEPO & $566739(115781)$ & 526734 & 535286 & 526161 & 550035 & \\
\hline \multirow[t]{2}{*}{ Von Willebrand Factor, \% } & Placebo & $164.0(68.4)$ & 143.4 & 155.1 & 161.0 & 140.8 & \multirow{2}{*}{$\begin{array}{l}11.0 \% \\
(-1.6 \%, 25.3 \%) \\
p=0.0887\end{array}$} \\
\hline & rHuEPO & $174.0(67.3)$ & 174.6 & 156.8 & 181.0 & 154.7 & \\
\hline \multirow[t]{2}{*}{$\mathrm{PF} 4, \mathrm{pg} / \mathrm{mL}$} & Placebo & $194624(116663)$ & 169825 & 163287 & 131027 & 115203 & \multirow{2}{*}{$\begin{array}{l}32.1 \% \\
(4.6 \%, 66.8 \%) \\
p=0.0207\end{array}$} \\
\hline & & 199970 (148748) & 170564 & 198478 & 228441 & 164724 & \\
\hline
\end{tabular}

Raw baseline (and SD) and EM (Estimated Mean) values of coagulation and endothelial activation markers after exercise at the different time points for both treatment groups, including the estimated differences between the treatment groups (95\% confidence interval) and $p$ value. Data analyzed with a mixed model analysis of variance with fixed factors treatment, time and treatment by time, random factor participant and the pre-value as covariate

However, even when using citrated plasma collection, levels of P-selectin can vary widely between studies (from on average approximately 20000 to $242000 \mathrm{pg} / \mathrm{mL}$ in healthy volunteers) (Caine and Blann 2003; Blann et al. 2000; van Poelgeest et al. 2018; Katayama et al. 1993), which might be partly due to differences between assays used (Kappelmayer et al. 2004). So how do the relative increases observed in our study relate to increased risk for clinically relevant thrombotic events? Little is known about the predictive value of P-selectin levels. One study in patients with first unprovoked venous thromboembolism, showed that patients with higher P-selectin levels during the follow-up had a higher risk of recurrence, with $14 \%$ higher levels in patients that would experience recurrence (Kyrle et al. 2007). In our study, increases in P-selectin levels were only slightly smaller after rHuEPO treatment and after the exercise test, and more than double after the race (increase of $34.1 \%$ ). Increases in P-selectin have also been observed after a mild in vivo lipopolysaccharide (LPS) challenge (up to $42 \%$ increases) (van Poelgeest et al. 2018). In addition, it is known that P-selectin levels are increased in different cardiovascular and hematological diseases. In thrombotic thrombocytopenic purpura and hemolytic uremic syndrome large differences in P-selectin levels of $274 \%$ and $245 \%$ with healthy controls were observed (Katayama et al. 1993). In a case-control study deep vein thrombosis was associated with a much smaller difference of 19\% (Blann et al. 2000). These findings combined indicate that exercise as well as rHuEPO use potentially are a risk factor for thrombosis.

\section{Effects on E-selectin}

E-selectin is specifically produced by endothelial cells upon shear stress or P-selectin exposure. Though deep vein thrombosis is not associated with increased systemic levels of E-selectin (Mosevoll et al. 2014), the molecule is a key factor for leukocyte recruitment and the subsequent inflammatory response of the vessel wall, which is key in the thrombotic process. E-selectin inhibition may be a therapeutic modality for thrombosis (Myers et al. 2014). Our study did not evaluate secondary markers for inflammation of the vessel wall but focused on inflammatory biomarkers that are directly related to platelet and endothelial activation. We found that the estimated mean levels of E-selectin after $\mathrm{rHuEPO}$ treatment were $5372 \mathrm{pg} / \mathrm{mL}$ compared to $4945 \mathrm{pg} / \mathrm{mL}$ in the placebo group, an increase of $9 \%$. Exercise increased E-selectin by $7 \%$ in the placebo group, but post-exercise E-selectin levels were $15 \%$ higher still in the rHuEPO group at $5868 \mathrm{pg} / \mathrm{mL}$, indicating there is an additive effect of rHuEPO and exercise. This leads to a combined increase in E-selectin of approximately $19 \%$ versus placebo in rest. Similar to what we describe for P-selectin, absolute baseline values of E-selectin are much smaller than reported previously for healthy volunteers (from 27800 to $54000 \mathrm{pg} / \mathrm{mL}$ in a review (Roldan et al. 2003) to $314000 \mathrm{pg} /$ 
$\mathrm{mL}$ in one other study (Raffray et al. 2017)). This review describes significant differences between cases and controls, with increases in E-selectin of 30-50\% for diabetes and hypertension. Much larger effects are observed after a mild intravenous in vivo LPS challenge (up to increases of 280\%) (van Poelgeest et al. 2018). There was no predictive value of E-selectin for myocardial infarction or death in the follow-up of patients with acute ischemic-type chest pain (Menown et al. 2003). However, patients with coronary artery disease showed higher risk of future death from cardiovascular causes if they had higher levels of iCAM, vCAM and E-selectin, the latter being $29 \%$ higher in the group of subjects that experienced events. Most of these reported differences and increases are only approximately twofold higher than the observed effect of the combination of rHuEPO and exercise, and so the combination of rHuEPO and exercise might indicate an increased risk of cardiovascular events compared to exercise alone based on the endothelial marker E-selectin.

\section{Other markers}

Finally, there is clear evidence that elevated levels of vWF are a predictive factor for ischemic heart disease, cardiovascular mortality and stroke in healthy individuals (Folsom et al. 1999; Jager et al. 1999; Rumley et al. 1999), and iCAM for myocardial infarction (Ridker et al. 1998). In our study, iCAM was unaffected by rHuEPO or the combination of rHuEPO and exercise, however, vWF showed a trend towards an increase after rHuEPO and exercise compared to exercise alone, albeit not significant.

\section{Mechanism}

The origin of E- and P-selectin increments during exercise and particularly upon rHuEPO treatment remains somewhat uncertain. P-selectin is localized in $\alpha$-granules of platelets, together with other platelet activation markers such as PF4. In addition, P-selectin is found in WeibelPalade bodies of endothelial cells, together with von Willebrand Factor, so the effect on P-selectin could be mediated both through platelet activation and endothelial activation. However, neither PF4, nor vWF were increased after rHuEPO treatment in rest, contradicting either of these mechanisms (although there was an increase in PF4 after the combination of rHuEPO and exercise). E-selectin on the other hand, is restricted to endothelial cells, but so are ICAM and vCAM, which were not increased after rHuEPO treatment in rest. These increases in Eand P-selectin without changes in other markers are in agreement with previous findings (Heinisch et al. 2012; Stohlawetz et al. 2000). One of these studies showed that E-selectin was already increased $24 \mathrm{~h}$ after rHuEPO dosing (Heinisch et al. 2012), indicating an acute mechanism and not an effect mediated through sheer stress by increases in hemoglobin; maturation of normoblasts in bone marrow lasts 5-7 days (McKenzie 1996). Although we did not measure levels in such short timeframe, it is interesting that E-selectin levels were already clearly increased at the first measurement 11 days after start of treatment (Fig. 1), whereas P-selectin levels only started showing increased levels 25 days after start of treatment (Fig. 2). This could indicate these effects are mediated by two different mechanisms. In summary, the mechanism through which rHuEPO increases E- and P-selectin is not completely clarified, and might be through enhancing both endothelial activation and platelet reactivity, as also suggested previously (Stohlawetz et al. 2000).

One limitation to this study is that participants might have been using supplements, other than the study mandated ascorbic acid and ferrous fumarate, that could potentially influence the reported markers. Similarly, diet of participants was not controlled. Concomitant medication other than paracetamol on the other hand was controlled; use was only allowed after consultation with the physician and, therefore, use was limited. Nevertheless, for any of these factors, it is important to note that the randomized design of the study should control for any effects on the outcome measures.

Another study limitation is that we did not evaluate vascular reactivity from a functional perspective, e.g., looking at NO metabolism, or evaluate effects on a broad range of inflammation markers. The focus of this study was on coagulation and platelet and endothelial activation, and therefore, the presented selection of markers was made. With the observed results, it would however be interesting to explore these additional pathways as well.

In conclusion, $\mathrm{rHuEPO}$ treatment resulted in endothelial activation in trained cyclists, based on increased levels of Pand E-selectin in rest. Exercise alone increased these markers as well, and the combination with $\mathrm{rHuEPO}$ use induced a cumulative effect for E-selectin, but not P-selectin. In addition, exercise induced hypercoagulability as observed by significant changes in all measured markers, including TAT, D-Dimer, aPTT, PF4 and Beta-TG. The combination of exercise and $\mathrm{rHuEPO}$ resulted in a larger PF4 response than exercise alone. Based on these markers, exercise potentially increases thrombotic risk, a risk that might be enhanced in combination with additional factors such as rHuEPO use.

Author contributions JH, JR, PG, FS, JD, JB, MM and AC were involved in the study design. JH, PG, FS, JB and AC were involved in the execution of the study. JH wrote the first draft and final manuscript with input from JP, DZ, JR, JD, PG, FS, HS, HtC, JB, MM and AC. JP and MM performed the coagulation and endothelial activation assays. All authors read and approved the manuscript. 
Funding This trial was an investigator-initiated study funded by the foundation Centre for Human Drug Research.

\section{Compliance with ethical standards}

Conflict of interest The authors declare that they have no conflict of interest.

Research involving Human Participants All procedures performed in studies involving human participants were in accordance with the ethical standards of the institutional research committee (Independent Ethics Committee of the Foundation 'Evaluation of Ethics in Biomedical Research' (Stichting Beoordeling Ethiek Biomedisch Onderzoek), Assen, The Netherlands) and with the 1964 Helsinki declaration and its later amendments or comparable ethical standards. The study was approved by this ethics committee and is registered under study number NTR5643 in the Dutch Trial Registry (Nederlands Trial Register, NTR).

Informed consent Informed consent was obtained from all individual participants included in the study prior to any study-related activity.

Open Access This article is licensed under a Creative Commons Attribution 4.0 International License, which permits use, sharing, adaptation, distribution and reproduction in any medium or format, as long as you give appropriate credit to the original author(s) and the source, provide a link to the Creative Commons licence, and indicate if changes were made. The images or other third party material in this article are included in the article's Creative Commons licence, unless indicated otherwise in a credit line to the material. If material is not included in the article's Creative Commons licence and your intended use is not permitted by statutory regulation or exceeds the permitted use, you will need to obtain permission directly from the copyright holder. To view a copy of this licence, visit http://creativecommons.org/licenses/by/4.0/.

\section{References}

Bielinski SJ, Berardi C, Decker PA, Kirsch PS, Larson NB, Pankow JS, Sale M, de Andrade M, Sicotte H, Tang W, Hanson NQ, Wassel CL, Polak JF, Tsai MY (2015) P-selectin and subclinical and clinical atherosclerosis: the Multi-Ethnic Study of Atherosclerosis (MESA). Atherosclerosis 240(1):3-9. https://doi.org/10.1016/j. atherosclerosis.2015.02.036

Blann AD, Noteboom WM, Rosendaal FR (2000) Increased soluble P-selectin levels following deep venous thrombosis: cause or effect? Br J Haematol 108(1):191-193

Bohlius J, Wilson J, Seidenfeld J, Piper M, Schwarzer G, Sandercock J, Trelle S, Weingart O, Bayliss S, Djulbegovic B, Bennett CL, Langensiepen S, Hyde C, Engert A (2006) Recombinant human erythropoietins and cancer patients: updated meta-analysis of 57 studies including 9353 patients. J Natl Cancer Inst 98(10):708714. https://doi.org/10.1093/jnci/djj189

Cadroy Y, Pillard F, Sakariassen KS, Thalamas C, Boneu B, Riviere D (2002) Strenuous but not moderate exercise increases the thrombotic tendency in healthy sedentary male volunteers. J Appl Physiol 93(3):829-833. https://doi.org/10.1152/japplphysi ol.00206.2002

Caine GJ, Blann AD (2003) Soluble p-selectin should be measured in citrated plasma, not in serum. Br J Haematol 121(3):530-532

Folsom AR, Rosamond WD, Shahar E, Cooper LS, Aleksic N, Nieto FJ, Rasmussen ML, Wu KK (1999) Prospective study of markers of hemostatic function with risk of ischemic stroke. The Atherosclerosis Risk in Communities (ARIC) Study Investigators. Circulation 100(7):736-742

Gunga HC, Kirsch K, Beneke R, Boning D, Hopfenmuller W, Leithauser R, Hutler M, Rocker L (2002) Markers of coagulation, fibrinolysis and angiogenesis after strenuous short-term exercise (Wingate-test) in male subjects of varying fitness levels. Int $\mathbf{J}$ Sports Med 23(7):495-499. https://doi.org/10.1055/s-2002-35070

Hamilton TC, Coyle D (2012) The secret race: inside the hidden world of the Tour de France. Random House Publishing Group, New York

Handa K, Terao Y, Mori T, Tanaka H, Kiyonaga A, Matsunaga A, Sasaki J, Shindo M, Arakawa K (1992) Different coagulability and fibrinolytic activity during exercise depending on exercise intensities. Thromb Res 66(5):613-616

Hegde SS, Goldfarb AH, Hegde S (2001) Clotting and fibrinolytic activity change during the $1 \mathrm{~h}$ after a submaximal run. Med Sci Sports Exerc 33(6):887-892

Heinisch BB, Vcelar B, Kapiotis S, Blann A, Wolzt M, Siller-Matula JM, Jilma B (2012) The effect of erythropoietin on platelet and endothelial activation markers: a prospective trial in healthy volunteers. Platelets 23(5):352-358. https://doi.org/10.3109/09537 104.2011.631621

Herren T, Bartsch P, Haeberli A, Straub PW (1992) Increased thrombin-antithrombin III complexes after $1 \mathrm{~h}$ of physical exercise. J Appl Physiol 73(6):2499-2504. https://doi.org/10.1152/jappl .1992.73.6.2499

Heuberger JA, Cohen Tervaert JM, Schepers FM, Vliegenthart AD, Rotmans JI, Daniels JM, Burggraaf J, Cohen AF (2013) Erythropoietin doping in cycling: lack of evidence for efficacy and a negative risk-benefit. Br J Clin Pharmacol 75(6):1406-1421. https://doi.org/10.1111/bcp.12034

Heuberger J, Rotmans JI, Gal P, Stuurman FE, Van't Westende J, Post TE, Daniels JMA, Moerland M, van Veldhoven PLJ, de Kam ML, Ram H, de Hon O, Posthuma JJ, Burggraaf J, Cohen AF (2017) Effects of erythropoietin on cycling performance of well trained cyclists: a double-blind, randomised, placebo-controlled trial. Lancet Haematol 4(8):e374-e386. https://doi.org/10.1016/ S2352-3026(17)30105-9

Jager A, van Hinsbergh VW, Kostense PJ, Emeis JJ, Yudkin JS, Nijpels G, Dekker JM, Heine RJ, Bouter LM, Stehouwer CD (1999) von Willebrand factor, C-reactive protein, and 5-year mortality in diabetic and nondiabetic subjects: the Hoorn Study. Arterioscler Thromb Vasc Biol 19(12):3071-3078

Jilma B, Eichler HG, Stohlawetz P, Dirnberger E, Kapiotis S, Wagner OF, Schutz W, Krejcy K (1997) Effects of exercise on circulating vascular adhesion molecules in healthy men. Immunobiology 197(5):505-512. https://doi.org/10.1016/S0171 -2985(97)80082-4

Kappelmayer J, Nagy B Jr, Miszti-Blasius K, Hevessy Z, Setiadi H (2004) The emerging value of P-selectin as a disease marker. Clin Chem Lab Med 42(5):475-486. https://doi.org/10.1515/ CCLM.2004.082

Katayama M, Handa M, Araki Y, Ambo H, Kawai Y, Watanabe K, Ikeda Y (1993) Soluble P-selectin is present in normal circulation and its plasma level is elevated in patients with thrombotic thrombocytopenic purpura and haemolytic uraemic syndrome. $\mathrm{Br}$ J Haematol 84(4):702-710

Kyrle PA, Hron G, Eichinger S, Wagner O (2007) Circulating P-selectin and the risk of recurrent venous thromboembolism. Thromb Haemost 97(6):880-883

Li N, He S, Blomback M, Hjemdahl P (2007) Platelet activity, coagulation, and fibrinolysis during exercise in healthy males: effects of thrombin inhibition by argatroban and enoxaparin. Arterioscler Thromb Vasc Biol 27(2):407-413. https://doi.org/10.1161/01. ATV.0000253906.19648.ac 
McKenzie SB (1996) Textbook of hematology, 2nd edn. Williams \& Wilkins, Baltimore

Menown IB, Mathew TP, Gracey HM, Nesbitt GS, Murray P, Young IS, Adgey AA, Prediction of recurrent events by DD, inflammatory markers in patients with normal cardiac troponin IS (2003) Prediction of Recurrent Events by D-Dimer and Inflammatory Markers in Patients with Normal Cardiac Troponin I (PREDICT) Study. Am Heart J 145(6):986-992. https://doi.org/10.1016/S0002 -8703(03)00169-8

Menzel K, Hilberg T (2011) Blood coagulation and fibrinolysis in healthy, untrained subjects: effects of different exercise intensities controlled by individual anaerobic threshold. Eur J Appl Physiol 111(2):253-260. https://doi.org/10.1007/s00421-010-1640-2

Mosevoll KA, Lindas R, Wendelbo O, Bruserud O, Reikvam H (2014) Systemic levels of the endothelium-derived soluble adhesion molecules endocan and E-selectin in patients with suspected deep vein thrombosis. Springerplus 3:571. https://doi. org/10.1186/2193-1801-3-571

Myers DD, Wrobleski SK, Kelsey K, Farris D, Jose DA, Peter HK, Sood SL, Wakefield TW, Magnani JL (2014) E-Selectin Inhibitor GMI-1271 Works in combination with low-molecular weight heparin to decrease venous thrombosis and bleeding risk in a mouse model. Blood 124(21):593

Nielsen HG, Lyberg T (2004) Long-distance running modulates the expression of leucocyte and endothelial adhesion molecules. Scand J Immunol 60(4):356-362. https://doi.org/10.111 1/j.0300-9475.2004.01486.x

Parker BA, Augeri AL, Capizzi JA, Ballard KD, Kupchak BR, Volek JS, Troyanos C, Kriz P, D'Hemecourt P, Thompson PD (2012) Effect of marathon run and air travel on pre- and post-run soluble d-dimer, microparticle procoagulant activity, and p-selectin levels. Am J Cardiol 109(10):1521-1525. https://doi.org/10.1016/j.amjca rd.2012.01.369

Pfeffer MA, Burdmann EA, Chen CY, Cooper ME, de Zeeuw D, Eckardt KU, Feyzi JM, Ivanovich P, Kewalramani R, Levey AS, Lewis EF, McGill JB, McMurray JJ, Parfrey P, Parving HH, Remuzzi G, Singh AK, Solomon SD, Toto R, Investigators T (2009) A trial of darbepoetin alfa in type 2 diabetes and chronic kidney disease. $\mathrm{N}$ Engl J Med 361(21):2019-2032. https://doi.org/10.1056/NEJMo a0907845

Posthuma JJ, Loeffen R, van Oerle R, Henskens YM, ten Cate H, Spronk HM, van der Meijden PE (2014) Long-term strenuous exercise induces a hypercoagulable state through contact activation. Thromb Haemost 111(6):1197-1199. https://doi. org/10.1160/TH13-11-0963

Posthuma JJ, van der Meijden PE, Ten Cate H, Spronk HM (2015) Short- and Long-term exercise induced alterations in haemostasis: a review of the literature. Blood Rev 29(3):171-178. https://doi. org/10.1016/j.blre.2014.10.005

Raffray L, Giry C, Thirapathi Y, Reboux AH, Jaffar-Bandjee MC, Gasque P (2017) Increased levels of soluble forms of E-selectin and ICAM-1 adhesion molecules during human leptospirosis. PLoS ONE 12(7):e0180474. https://doi.org/10.1371/journ al.pone. 0180474

Rehman J, Mills PJ, Carter SM, Chou J, Thomas J, Maisel AS (1997) Dynamic exercise leads to an increase in circulating ICAM-1: further evidence for adrenergic modulation of cell adhesion. Brain Behav Immun 11(4):343-351. https://doi.org/10.1006/ brbi.1997.0498

Ridker PM, Hennekens CH, Roitman-Johnson B, Stampfer MJ, Allen J (1998) Plasma concentration of soluble intercellular adhesion molecule 1 and risks of future myocardial infarction in apparently healthy men. Lancet 351(9096):88-92. https://doi.org/10.1016/ S0140-6736(97)09032-6

Rocker L, Drygas WK, Heyduck B (1986) Blood platelet activation and increase in thrombin activity following a marathon race. Eur J Appl Physiol Occup Physiol 55(4):374-380

Rocker L, Mockel M, Westpfahl KP, Gunga HC (1996) Influence of maximal ergometric exercise on endothelin concentrations in relation to molecular markers of the hemostatic system. Thromb Haemost 75(4):612-616

Roldan V, Marin F, Lip GY, Blann AD (2003) Soluble E-selectin in cardiovascular disease and its risk factors. A review of the literature. Thromb Haemost 90(6):1007-1020. https://doi.org/10.1160/ th02-09-0083

Rumley A, Lowe GD, Sweetnam PM, Yarnell JW, Ford RP (1999) Factor VIII, von Willebrand factor and the risk of major ischaemic heart disease in the Caerphilly Heart Study. Br J Haematol 105(1):110-116

Stohlawetz PJ, Dzirlo L, Hergovich N, Lackner E, Mensik C, Eichler HG, Kabrna E, Geissler K, Jilma B (2000) Effects of erythropoietin on platelet reactivity and thrombopoiesis in humans. Blood 95(9):2983-2989

van Poelgeest EP, Dillingh MR, de Kam M, Malone KE, Kemper M, Stroes ESG, Burggraaf J, Moerland M (2018) Characterization of immune cell, endothelial, and renal responses upon experimental human endotoxemia. J Pharmacol Toxicol Methods 89:39-46. https://doi.org/10.1016/j.vasen.2017.10.004

Wang JS, Jen CJ, Kung HC, Lin LJ, Hsiue TR, Chen HI (1994) Different effects of strenuous exercise and moderate exercise on platelet function in men. Circulation 90(6):2877-2885

World Anti-Doping Agency (2018) Prohibited List 2018. https://www. wada-ama.org/sites/default/files/prohibited_list_2018_en.pdf. Accessed 7 Aug 2018

Publisher's Note Springer Nature remains neutral with regard to jurisdictional claims in published maps and institutional affiliations. 